\title{
O DEBATE REGRADO E A CONSTRUÇÃO DE COMPETÊNCIAS E HABILIDADES ORAIS NO NONO ANO DO ENSINO FUNDAMENTAL
}

Natália Coêlho Bagagim ${ }^{1}$

\section{Apresentação}

A oralidade é um eixo norteador do letramento de suma importância, na qual está inserida na Base Nacional Curricular Comum. Nesse contexto, Marcuschi (2001) salienta que "Não se trata de ensinar a falar, trata-se de identificar a imensa riqueza e variedade de usos da língua." Nessa perspectiva, a função da escola não é ensinar o aluno a falar por intermédio do "estudo com a oralidade", visto que todo indivíduo já possui a língua materna internalizada, mas possibilitá-lo reconhecer os usos orais nas mais diversas situações comunicativas, capacitando-os a empregar os gêneros textuais orais de acordo com a realização do contexto da fala: da mais informal a mais formal, (Marcuschi, 2001).

Nessa ótica, o ensino da oralidade deve se desenvolver por intermédio de gêneros que apoiam a aprendizagem escolar, tanto no ensino da Língua Portuguesa quanto das demais áreas do conhecimento, PCNs (1998). Com base nisso, foi desenvolvido o trabalho com o gênero debate regrado com os estudantes do nono ano do Ensino Fundamental a fim de que os mesmos percebessem a oralidade como prática social com fins comunicativos (Marcuschi, 2001).

O presente trabalho traz um relato de experiência docente da abordagem do gênero debate regrado para o desenvolvimento das competências e habilidades orais dos aprendizes do nono ano de uma escola municipal. As atividades foram realizadas mediante sequência didática de modo que todos os objetivos pudessem ser alcançados.

\footnotetext{
${ }^{1}$ Graduada em Letras, Português, pela Universidade Federal Rural de Pernambuco (UFRPE). Pós-graduada em Língua Portuguesa e Literatura Brasileira pela Universidade Candido Mendes - UCAM. Mestranda do PROFLETRAS / UFCG - Campus Cajazeiras-PB. Professora da Escola Municipal João Neném de Macêdo em Ouricuri-PE.
} 
Caracterização da escola e dos alunos

A experiência ocorreu em uma escola pública municipal, localizada na zona rural, aproximadamente vinte e cinco quilômetros da sede, que possui características simples e humildes, da cidade de Ouricuri-PE. A escola atende alunos da Educação Infantil e Ensino Fundamental Séries Iniciais, no turno matutino e o Ensino Fundamental Séries Finais no turno vespertino. Existem sete salas de aula e a no colégio cerca de vinte e três professores incluindo as assistentes. $\mathrm{Na}$ instituição não há laboratórios de informática e nem tampouco recursos tecnológicos como mídia, DVD e outros.

A turma do nono ano do Ensino Fundamental era composta por quarenta adolescentes com idade entre 13 e 17 anos, em sua maioria de classe média baixa, residentes em sítios próximos ao Distrito da escola. Observou-se, ainda, que muitos alunos tinham dificuldades de se expressarem por sentirem vergonha, além de terem um conhecimento de mundo limitado, advindo da carência de leituras e de estímulos e incentivos a serem indivíduos críticos. Dessa forma, o trabalho em evidência foi crucial para romper ao menos em parte essas barreiras.

\section{Pressupostos teóricos}

A oralidade é um eixo norteador do ensino da Língua Portuguesa bastante importante, uma vez que ela está presente em diversas situações e, é por meio dela, que o indivíduo exprime seu ponto de vista sobre um tema, negocia, refuta argumentos, relata experiências, etc., Assim, partindo dessa premissa, é primordial que a escola desenvolva atividades que priorizem a linguagem oral de forma significativa para o aluno, "trata-se de propor situações didáticas nas quais essas atividades façam sentido de fato". (PCNs 1998). Dessa forma, a abordagem da oralidade não condiz em apenas pedir ao estudante leitura em voz alta, ao contrário disso, a linguagem oral só tem sentindo mediante a inserção dos gêneros textuais em situações de uso na prática social como: exposição, entrevista, debate e tantos outros.

Nessa perspectiva, o foco do trabalho oral desenvolvido foi com base no gênero debate regrado. Costa (2009) em seu Dicionário de Gêneros conceituou o termo "debate" como uma discussão acirrada em que há argumentos e razões em defesa de uma opinião ou contra um argumento. Assim, é evidente que o debate regrado é um gênero argumentativo oral que se realiza por meio da interação entre pessoas que desejam conhecer e discutir diferentes pontos de vista sobre um determinado tema polêmico.

O debate exige que o participante tenha conhecimentos acerca do assunto em questão e que desenvolva argumentos sólidos para concordar ou discordar das opiniões apresentadas e o termo 
regrado está em consonância com a organização das falas dos envolvidos do debate a fim de não ocorrer conflitos e desrespeito, Dolz e Schneuwly (1998).

Para a ocorrência de um debate, faz-se necessário em primeira instância verificar os saberes que os estudantes já têm sobre o gênero, o tipo argumentativo, a linguagem adequada, o tom da voz, o público-alvo de acordo com o tema em discussão, a escuta do outro e a retomada do discurso, os conectores coesivos, as marcas linguísticas, o respeito com o posicionamento do outro, a coerência dos argumentos, etc. Após a análise e abordagem dos pontos evidenciados é primordial a indicação de leituras a respeito do tema a ser abordado na discussão, objetivando a construção dos próprios argumentos dos discentes com base no conhecimento prévio que eles já possuem sobre a temática, Freire (1994) comprova o dito afirmando que a "leitura precede a palavra, daí que a posterior leitura desta não possa prescindir da continuidade da leitura daquele".

Ainda nesse contexto, ressalta-se que o debate regrado é predominantemente oral. Porém, o gênero precisa da modalidade escrita para se estabelecer, uma vez que há grifo das pesquisas realizadas, da coleta de dados e as anotações dos pontos principais feitas anteriormente no momento do planejamento da argumentação, além disso, durante a apresentação oral a escrita também está presente, pois:

[...] é necessário anotar as observações para lembrar-se delas ou para transmiti-las aos outros; é preciso transcrever certas expressões para comentá-las [...]. Mesmo que a escrita não seja o mediador do processo de ensino-aprendizagem do oral, acaba por se constituir num instrumento muitas vezes indispensável (Dolz; Schneuwly; Pietro, 2004).

Desse modo, portanto, é imprescindível preparar o aluno para o uso da linguagem oral para situações reais de comunicação social. Logo, o gênero debate regrado propicia o aperfeiçoamento das competências e habilidades orais dos educandos, formando-os seres mais críticos que saibam identificar e apontar os pontos positivos e negativos dos assuntos polêmicos que ocorrem na sociedade.

\section{Descrição da atividade}

A realização do trabalho ocorreu na única turma do nono ano do Ensino Fundamental da escola supracitada, tendo como objetivo geral desenvolver as habilidades de expressão dos pontos de vista por intermédio da modalidade oral. Nesse contexto, foi pensado em um assunto polêmico que faz parte da realidade social de todos os indivíduos para se discutir e realizar o debate regrado. Mas antes de apresentar a temática em questão, foi abordado com muita ênfase o eixo oralidade, na qual foi 
questionado a respeito do uso da modalidade oral nas mais diversas situações, tais como: Qual é a modalidade que vocês mais utilizam para se expressar no dia a dia, a modalidade oral ou escrita? Você se expressa da mesma maneira em todas as situações, isto é, a sua fala espontânea aqui na sala de aula com os colegas deve ser igual em uma entrevista de emprego, por exemplo? Você conhece algum gênero textual que predomina a oralidade? Saber utilizar a linguagem oral de acordo com as particularidades do gênero é importante?

Após a abordagem do eixo oralidade, foi apresentado o gênero debate regrado, realizando a averiguação dos conhecimentos prévios dos discentes sobre o gênero em questão, indagando-os: 0 que significa debate? Por que regrado? Posteriormente, foram explanadas dialogicamente as características do gênero, sua função, linguagem empregada, como é feito o planejamento, os princípios e os procedimentos para a realização do debate, etc. Na sequência, a fim de que os educandos conhecessem melhor as peculiaridades do texto, solicitou-se a leitura e análise da transcrição de um debate exposta no livro didático de William Cereja e Thereza Cochar Magalhães com o tema "A violência na sociedade hoje e as causas da violência." Nesse momento, os alunos perceberam que o tema debatido no texto era polêmico e que permitia diferentes opiniões nas quais os participantes fizerem uso de argumentos para fundamentar os seus pontos de vista, além de terem notado que os envolvidos no debate ora discordavam ora concordavam com o colega e argumentava a razão de tal ato. Ademais, foi verificado pelos aprendizes na transcrição analisada, as expressões como, "eu acho que, na minha opinião, a meu ver" que foram empregadas pelos debatedores e que são aceitáveis em um debate.

Ao concluir a atividade citada, foi apresentado o tema para a realização do debate regrado "Gravidez na adolescência: o papel da família, da escola, da mídia e do governo na conscientização dos jovens." A escolha desse tema foi sugestão do livro didático "Português Linguagens" de Cereja e Magalhães que foi adotada por ser uma temática que predomina a função social, visto que os envolvidos no estudo são adolescentes que se encontra na fase de desenvolvimento da sexualidade, dessa forma, é de suma importância a discussão do assunto. Foi solicitada a leitura dos cincos textos de apoio presentes no livro que abordavam a gravidez na adolescência no Brasil, além da distribuição de vários textos impressos sobre o tema com dados, estatísticas e depoimentos, pois muitos alunos não tinham acesso à internet para pesquisar sobre o assunto. Na aula seguinte, foram evidenciadas as regras para a realização do debate e em conjunto com a classe foi escolhido um colega para ser o moderador do debate. Todos os alunos foram convidados a participarem do debate, uma vez que era o primeiro contato deles com a exposição oral, muitos se diziam envergonhados em falar. A avaliação do debate consistia em observar o desenvolvimento de cada um no debate com suas respectivas colocações, à dinamicidade das trocas, etc. 
Foi oferecido um tempo de oitos dias para que o aluno se preparasse com base em leituras para a realização do debate. No dia do evento, a professora de Ciências da referida escola era convidada especial para assistir a apresentação dos alunos e na sequência realizar uma palestra sobre o tema, realizando assim, a conclusão e socialização do tema de modo esclarecedor. Assim, durante o debate foi percebido o quanto eles se superaram, mesmo diante do nervosismo. Foi notada a coerência nos argumentos, a concordância e discordância das opiniões, o controle do moderador em mediar o debate, as anotações de pontos importantes para retomar a discussão. Porém, alguns alunos se recusaram a participar alegando vergonha e nervosismo, o que é compreensível. Após a realização do debate regrado que durou cerca de 30 minutos, a mestre em Ciências da escola iniciou-se a palestra elogiando as colocações dos alunos e trazendo mais informações e conhecimentos acerca do assunto. $\mathrm{Na}$ aula seguinte, os estudantes comentaram a respeito da exposição oral dizendo que foi uma experiência muito agradável, apesar de todo o nervosismo sentindo antes e durante o debate.

\section{Avaliação dos resultados}

Ao final do trabalho com o gênero debate regrado, foram perceptíveis mudanças significativas na aprendizagem dos alunos, pois eles passaram a utilizar a oralidade, especialmente, ao comentar e discutir textos com mais propriedade. Além disso, os indivíduos passaram a responder em atividades ou dizer "sim" ou "não" na fala de modo justificado com base em argumentos fundamentados.

É importante salientar que outras habilidades foram desenvolvidas com o gênero em questão, pois antes da realização do debate, os estudantes realizaram muitas leituras e fizeram registros escritos dos pontos considerados relevantes para a discussão. Desse modo, a abordagem do gênero contribuiu para a ativação do senso crítico e para o desenvolvimento de competências e habilidades orais, escritas e leitoras. Embora pareça ser algo tão simples, para a realidade dos alunos foi algo novo e prazeroso, visto que eles nunca tinham participado de um debate e acreditavam não serem capazes de tal ato. Com relação aos que se recusaram a participar alegando vergonha e nervoso foi considerado natural, levando em consideração a carência do trabalho com os gêneros orais nas séries anteriores, sendo o debate regrado o primeiro que eles tiveram contato. Ademais, é válido realçar que a criticidade também foi consolidada, pois na abordagem temática os participantes adotaram um ponto de vista baseado em aspecto positivo e negativo, no qual foi sustentando mediante a defesa de argumentos sobre a questão debatida. 


\section{Considerações finais}

Com base no trabalho realizado, ficou nítido que os alunos são capazes de desempenhar belíssimas apresentações orais e que o papel do professor é fundamental na mudança significativa da turma. É preciso acreditar e desafiar os sujeitos da aprendizagem em busca da superação do medo, da timidez e de tantos outros obstáculos que impedem o conhecimento.

A busca por conhecimentos acerca do assunto, a troca de experiências entre eles e a realização do debate, deixou-me entusiasmada e feliz por ter conseguido alcançar o objetivo proposto e por ter percebido que é possível desenvolver as habilidades orais dos educandos por intermédio de gêneros textuais.

Desse modo, portanto, a experiência do gênero supracitado foi muito enriquecedora para o ensino-aprendizagem, pois por meio dela outras habilidades foram estabelecidas como a leitura, a escrita, a argumentação, a coerência, a linguagem, etc. Logo, enquanto professora, estou convicta de que é preciso trabalhar com gêneros que apoiam a aprendizagem significativa do aluno.

\section{Referências}

BRASIL. Secretaria de Educação Fundamental. Parâmetros Curriculares Nacionais: terceiro e quarto ciclos do ensino fundamental - língua portuguesa. Brasília, 1998.

CEREJA, W.R, MAGALHÃES, T.C. Português linguagens. 9 ed. São Paulo: Saraiva, 2015.

COSTA, Sérgio Roberto. Dicionário de gêneros textuais. 2. ed. Belo Horizonte: Autêntica, 2009.

DOLZ, J. \& SCHNEUWLY, B. 1998. Pour un enseignement de l'oral. Initiation aux genres formels à l'école.Paris:ESFéditeur. (Disponívelem: $\underline{\text { http://www.scielo.br/scielo.php?script=sci arttext\&pid=S010 }}$ 2-44502009000100002 acesso: 25abril. 2018.

DOLZ, Joaquim; SCHNEUWLY, Bernard; PIETRO, Jean-François de. Relato da elaboração de uma sequência: o debate público. In: SCHNEUWLY, Bernard; DOLZ, Joaquim. Gêneros orais e escritos na escola. Tradução e organização de Roxane Rojo e Glaís Sales Cordeiro. Campinas, SP: Mercado de Letras, 2004. p. 247-278.

FREIRE, Paulo. A importância do ato de ler: em três artigos que se completam. 29. Ed. São Paulo: Cortez, 1994.

MARCUSCHI, Luiz Antônio. Da fala para a escrita: atividades de retextualização. São Paulo: Cortez, 2001. 


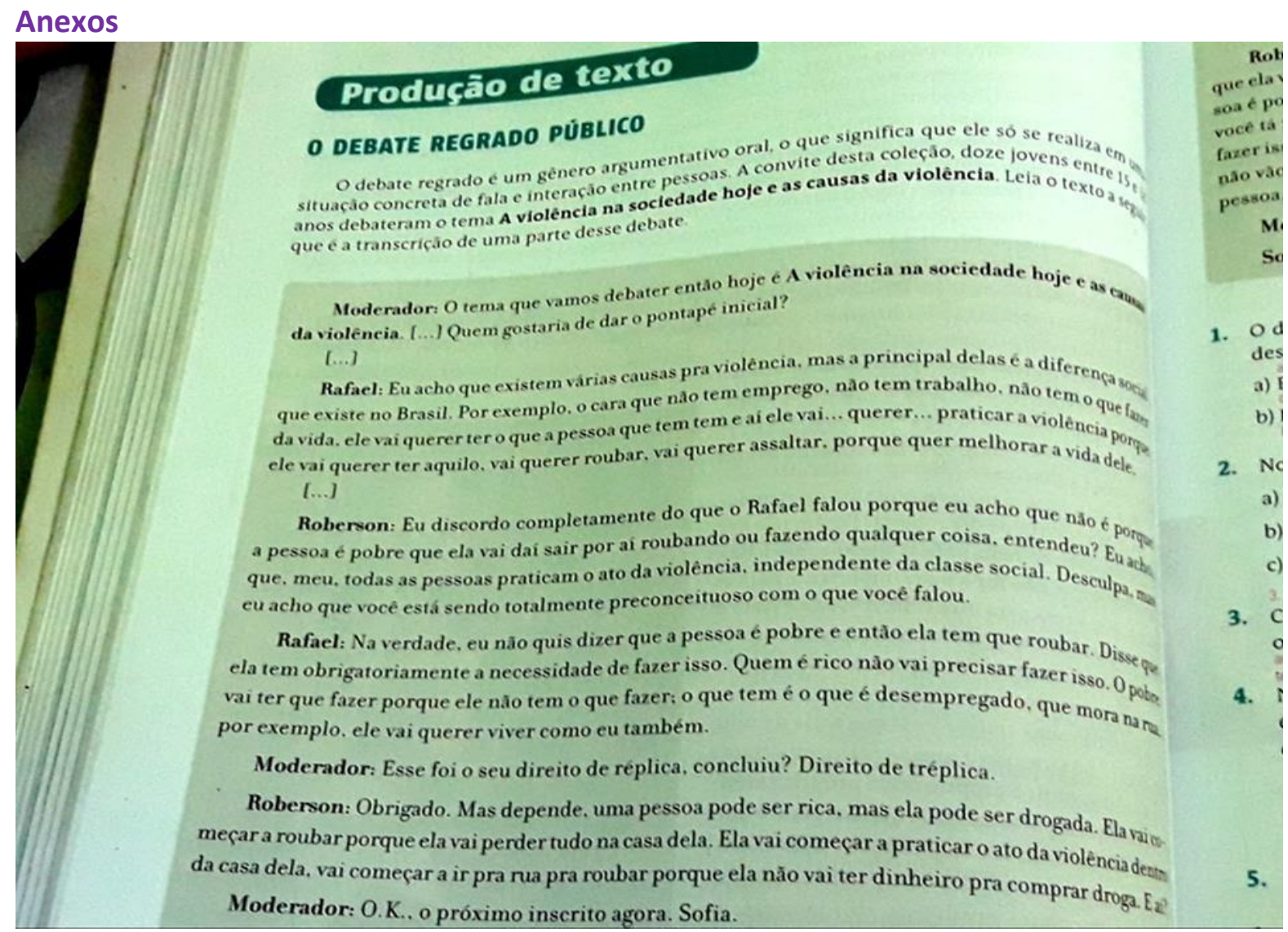

CEREJA, W.R, MAGALHÃES, T.C. Português linguagens. 9 ed. São Paulo: Saraiva, 2015.

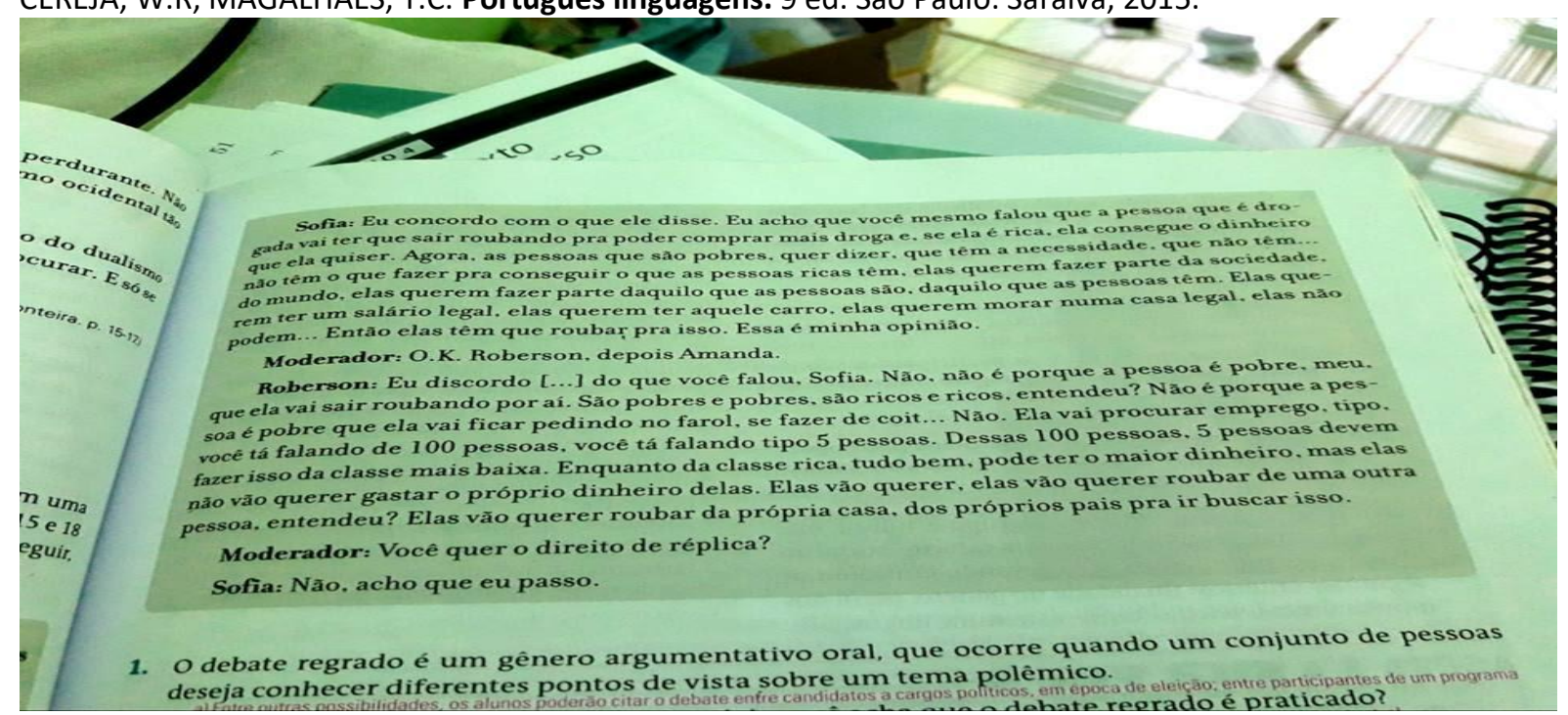

CEREJA, W.R, MAGALHÃES, T.C. Português linguagens. 9 ed. São Paulo: Saraiva, 2015. 


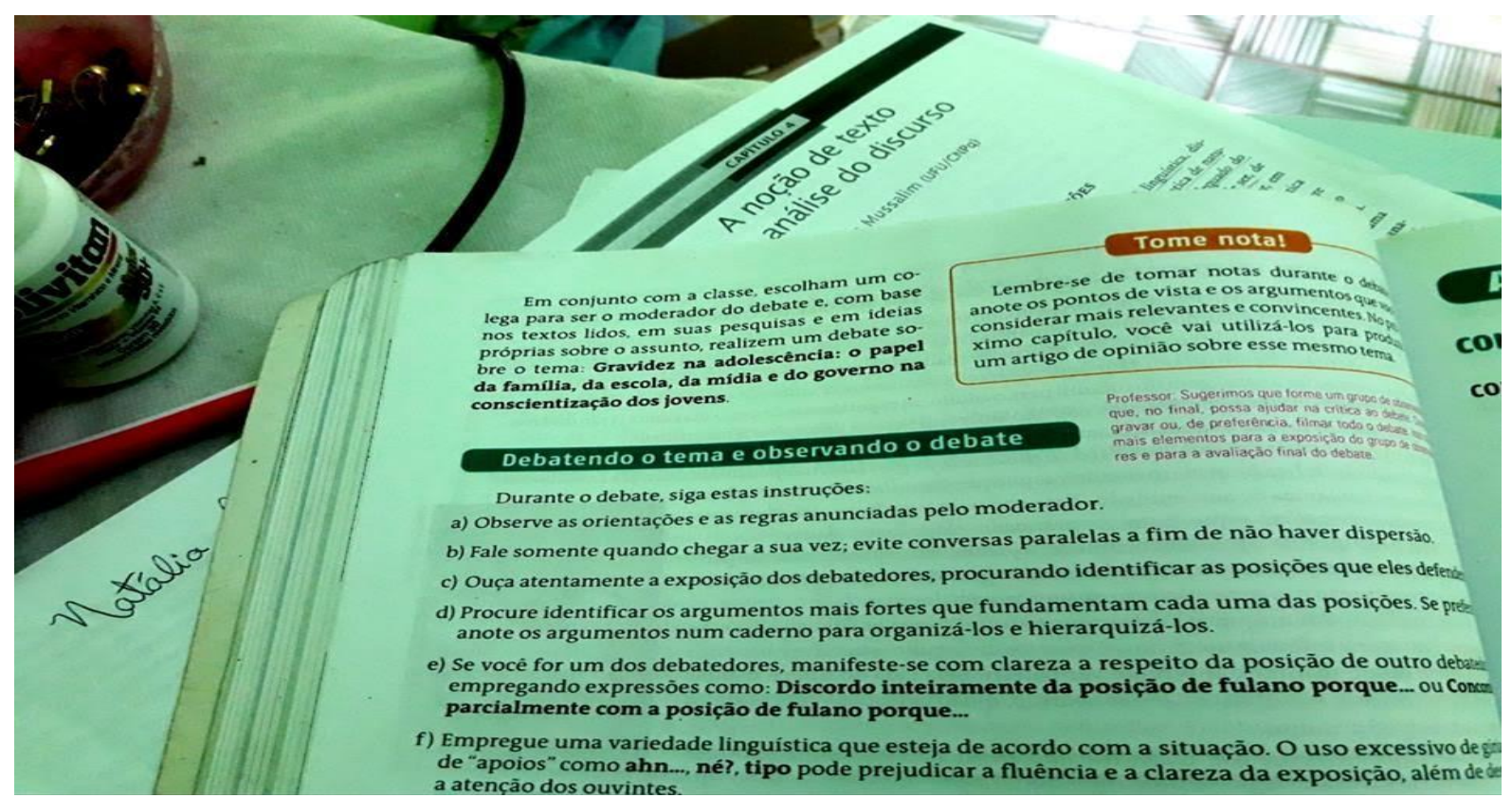

CEREJA, W.R, MAGALHÃES, T.C. Português linguagens. 9 ed. São Paulo: Saraiva, 2015.
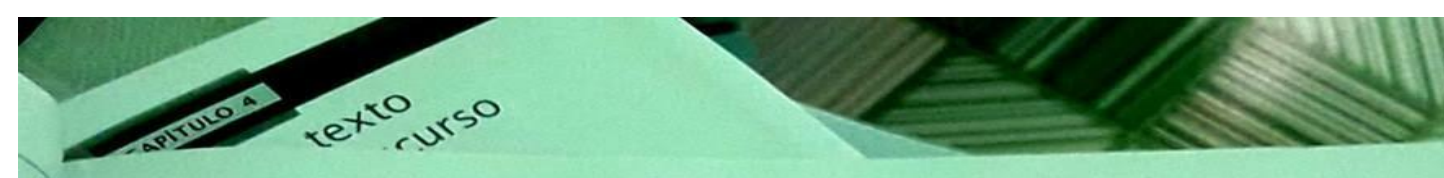

\section{Planejamento e realizaçâo do debate}

para participar do debate, siga estas orientaçōes:

- Pense sobre o tema e assuma um ponto de vista, de acordo com sua opiniâo sobre o assunto debatido.

- Fundamente sua opinião com bons argumentos, com motivos e ex. plicaçôes.

- Procure utilizar dados e fatos como exemplo em sua argumentação Quanto mais claros e precisos forem seus argumentos, mais facilidade você terá para convencer seus interlocutores.

- Faça anotaçóes dos pontos principais que você defenderá e dos argumentos a serem utillizados: elas podem servir como guia para conduzir seu raciocínio.

- Leia o quadro "Príncípios e procedimentos para a realização de um debate democrático"

- Direcione sua fala para o público e cuidado com a impostação da voz: não fale nem muito alto. nem

Direcione sua fala para o público e cuidado com a impostaça da voz: náo fale nem mude com sua fala. muito baixo, nem gritando, nem sussurrando. Procure passar segurança e credibilida que você possa

- Fique atento aos argumentos e contra-argumentos dos out

refutá-los adequadamente, sem. no entanto, ser agressivo. - Utilize uma linguagem adequada ao debate, sem o uso excessivo de gírias e de expressoes cono "tipo", "assim", "né",
uma conversa informal, ou repetiça excessiva de uma mesma expressão, como "tá", entre outras.

- Se possivel, filme o debate. Assim, posteriormente, todos poderão assistir a ele
de observar aspectos positivos e negativos e aprimorar os próximos debates.

CEREJA, W.R, MAGALHÃES, T.C. Português linguagens. 9 ed. São Paulo: Saraiva, 2015. 


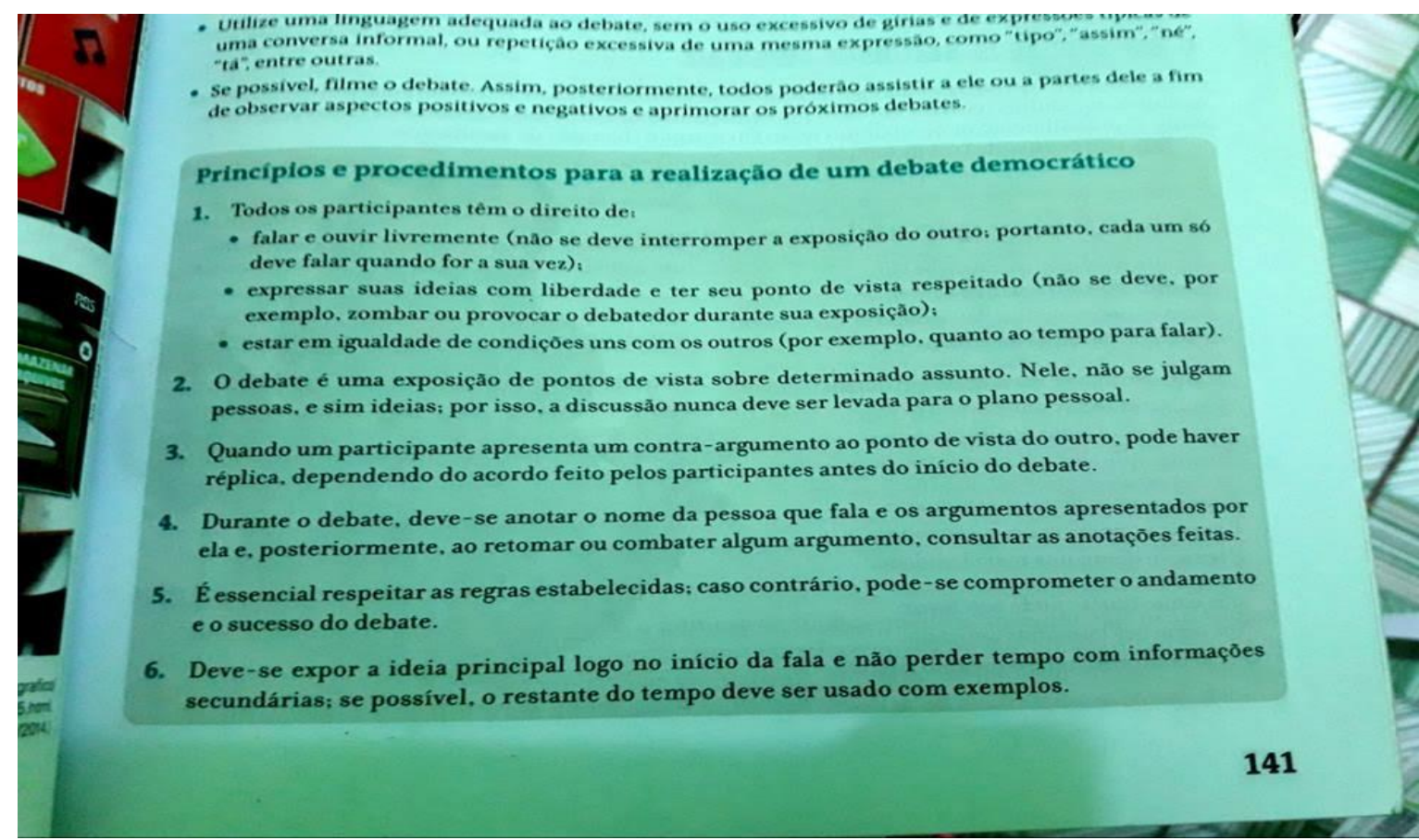

CEREJA, W.R, MAGALHÃES, T.C. Português linguagens. 9 ed. São Paulo: Saraiva, 2015.

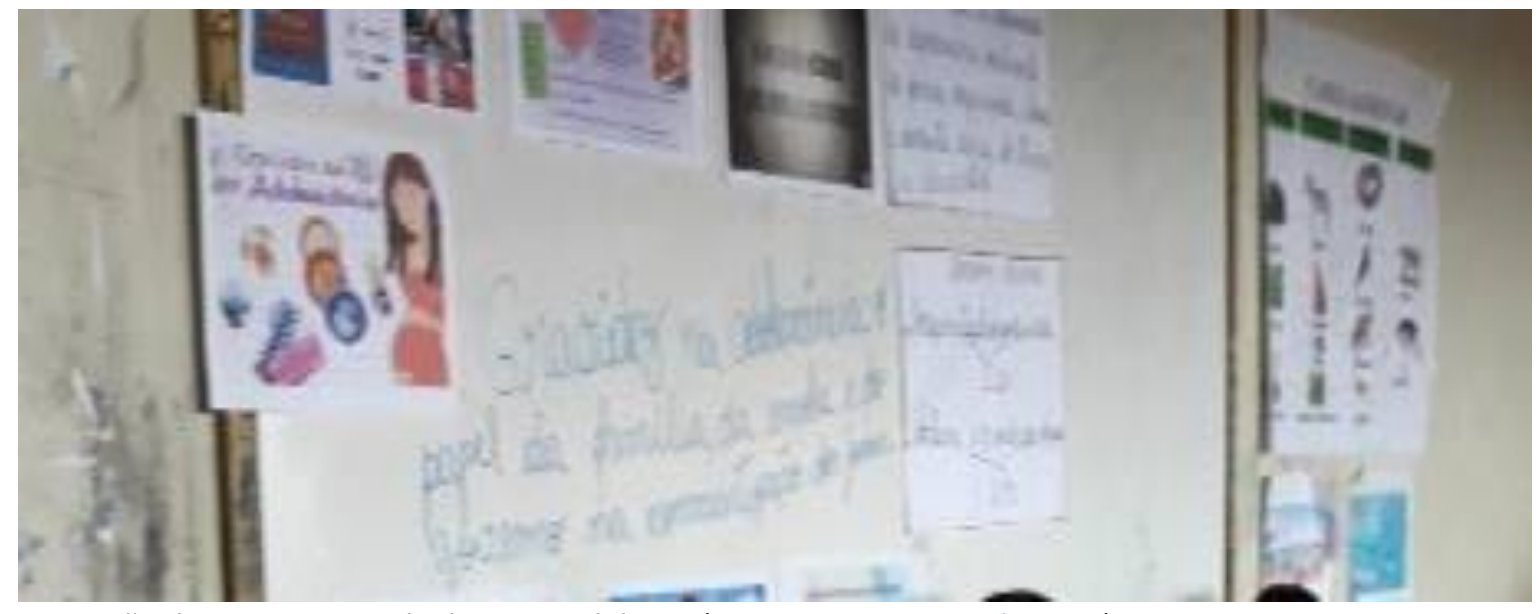

Exposição de cartazes na sala durante o debate. (Imagens: www.google.com )

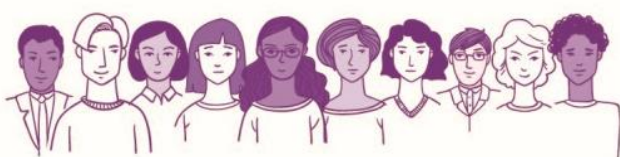

